\title{
MEMAHAMI KARAKTERISTIK BAHASA AL-QUR`AN DALAM PERSPEKTIF BALAGHIYAH
}

\author{
Marzuki Mustamar
}

Dosen Jurusan Bahasa dan Sastra Arab,

Fakultas Humaniora dan Budaya, Universitas Islam Negeri (UIN) Malang.

Jalan Gajayana No. 50 Telepon (0341) 551354, Faksimile (0341) 572533 Malang 65144

Pengasuh Ponpes Sabilurrosyad, Jalan Candi Blok VI C Gasek, Karang Besuki, Sukun, Malang. Telepon (0341) 564446.

\begin{abstract}
The nature of language is to express that someone exists, or in other word, expressing the existence. Through the revelation Allah introduces his existence to the creature. It can also be seen from the qudsi hadists popular among the sufi. It is said that Dawud asked to Allah, why do you create the creature? Allah answered, "I am the hidden hemisphere and I want to be known. For that reason I create the creatures so that I am known".
\end{abstract}

Keywords

Self-Existence, Metaphor, Communication

\section{Pendahuluan}

Makna sentral pemberian wahyu adalah pemberian informasi, yaitu sebuah hubungan komunikasi antara dua pihak dengan menyampaikan pesan secara samar dan rahasia (Al-Qatthan, tt:32). Situasi komunikasi dalam konteks wahyu al-Qur'an sangat berbeda dengan situasi komunikasi lainnya. Dua sisi komunikasi yang mendasar dalam proses pewahyuan adalah Allah SWT di satu pihak dan Rasul 
yang manusiawi di pihak lain. Proses ini memiliki cara-cara tertentu sebagaimana yang diungkap dalam al-Qur`an. Namun pada prinsipnya, seperti yang dikemukakan Aristoteles bahwa proses komunikasi melibatkan tiga unsur yang tidak bisa dipisahkan, yaitu pembicara (speaker), pesan (message) dan pendengar (listener) (Mulyana, 2001134).

Berkomunikasi pada hakikatnya adalah untuk menunjukkan dirinya eksis, atau untuk menyatakan tentang eksistensi diri. Bahasa sebagai salah satu media berkomunikasi merupakan ekspresi dan eksternalisasi diri agar dirinya dipahami dan diterima orang lain, dan sebaliknya, lewat bahasa pula seseorang melakukan identifikasi dan internalisasi nilai-nilai serta informasi yang dijumpai di sekelilingnya. Tidak berlebihan kiranya, ketika Allah memberikan wahyu kepada Nabi Muhammad SAW maka semenjak itu beliau bertindak sebagai perantara antara Tuhan dan dunia (Izutsu, 1997:197). Artinya, melalui wahyu Allah SWT memperkenalkan diri-Nya kepada makhluk. Sebagaimana dikutip Sachiko Murata (1999:93), sebuah hadis qudsi yang sangat populer dikalangan para sufi, dikatakan bahwa Dawud bertanya kepada Allah, mengapa Engkau menciptakan makhluk? Allah SWT lantas menjawab, "Aku adalah khazanah tersembunyi dan Aku ingin (suka) diketahui. Karena itu, Aku menciptakan makhluk agar Aku diketahui".

Bahasa atau kata-kata adalah kategori-kategori untuk merujuk pada obyek tertentu. Suatu kata hanya mewakili realitas, tetapi bukan realitas itu sendiri. Dengan demikian, kata-kata pada dasarnya bersifat parsial, tidak melukiskan sesuatu secara eksak. Sebab itu, ada kalanya kita sulit menamai suatu obyek karena tidak semua kata-kata tersedia untuk itu. Selain itu, kata-kata juga bersifat ambigu, karena kata-kata merepresentasikan persepsi dan interpretasi orang-orang yang berbeda, yang menganut latar-belakang sosial budaya yang berbeda-beda pula. Sehingga terdapat berbagai kemungkinan untuk memaknai kata-kata tersebut. Konsep dan lain-lain (dll.), dan sebagainya (dsb.), dan seterusnya (dst.) sebenarnya menunjukkan bahwa tidak ada suatu pernyataan yang dapat mewakili dunia nyata, dan meskipun terdapat pengetahuan yang komprehensif mengenai suatu obyek akan selalu ada hal lain atau hal 
baru untuk dipertimbangkan. Dan sangat beralasan apabila seseorang dalam berkomunikasi menggunakan bahasa metaforis untuk mengungkapkan pikiran, ide, dan gagasan karena tidak ada bahasa yang tepat untuk mewakilinya, atau ada tujuan-tujuan lain karena bahasa metaforis lebih simple dan padat dengan makna.

Dalam dunia empiris saja kita sulit menghindari ungkapanungkapan seperti itu, apalagi dalam bahasa al-Qur'an yang sangat menekankan aspek believing dan understanding ketimbang explaining dan describing. Jadi, jelas dalam bahasa al-Qur`an banyak sekali ditemukan ungkapan metaforis meskipun keberadaannya cukup berpotensial bagi munculnya spekulasi dan relativisme pemahaman. Dan lebih dari itu, bahasa metaforis juga diyakini memiliki kekuatan yang bisa membangkitkan imajinasi kreatif untuk membuka wilayah pemahaman baru yang batas akhirnya belum diketahui.

Bahasa al-Qur'an memiliki hakikat yang khusus, berbeda dengan bahasa-bahasa yang lain. Karena bahasa al-Qur`an bukan hanya mengacu pada dunia empiris semata, melainkan juga mengatasi ruang dan waktu, bersifat metafisik dan Ilahiyah. Dengan demikian, untuk memahami ayat-ayat al-Qur'an tidak mungkin hanya berdasarkan pada kaidah-kaidah linguistik semata. Sebab itu, sangat realistis bilamana kemudian dikembangkan bahasa metafor dan analogi (majaz-tasybih) (Kaelan, 2003:72). Sebab, bahasa metafor dan analogi dapat memberikan jembatan rasio manusia yang serba terbatas dengan dimensi Ilahiyah dan metafisik yang tak terbatas. Bahasa metafor atau bahasa simbol yang lazim di kalangan kritikus sastra dan pemikir muslim klasik dikenal dengan istilah majaz, tasybih, atau kinayah. Suatu gaya bahasa yang sudah dikenal di kalangan sastrawan Arab dan sering dieksploatasikan dalam karya sastra yang diciptakan untuk menghilangkan kegelisahan dan kepenatan hidup guna mencari kebahagiaan dan kesenangan walaupun hanya terjadi dalam dunia imajinasi.

Dalam dunia tasawwuf, bila kita cermati juga banyak ungkapanungkapan metaforik-simbolik. Yaitu, sebuah ungkapan karena ketidakmampuan narasi deskriptif untuk menjelaskan dan 
menghadirkan pengalaman unik, realitas absolut, intuisi dan imajinasi yang datang tiba-tiba. Sehingga literatur sufi seringkali memperoleh kritikan pedas terutama dari kalangan ulama fiqh yang terbiasa dengan, dan memang menghendaki, narasi deskriptif yang jelas dan tegas karena fiqh memang ilmu yang bertujuan memproduksi diktum hukum.

Dalam diskursus kajian bahasa Arab, istilah metafora diidentikkan dengan ilm al-bayan, yang mencakup 3 (tiga) bidang kajian, yaitu: 1) majaz, 2) tasybih dan 3) kinayah. Metafora adalah semacam analogi yang membandingkan dua hal secara langsung dalam bentuk yang singkat. Berbeda dengan tasybih (simile), yaitu perbandingan yang bersifat ekspilisit, sehingga memerlukan kata-kata seperti, bagaikan, dan sebagainya (Keraf, 2004:138). Menurut Abdul Wahab (1998:65), metafora adalah ungkapan kebahasaan yang tidak dapat diartikan secara langsung dari lambang yang dipakai, melainkan dari prediksi yang dapat dipakai baik oleh lambang maupun oleh makna yang dimaksudkan oleh ungkapan kebahasaan itu. Berdasarkan definisi di atas maka dalam tulisan ini, penulis hanya membatasi pada kajian majaz, tasybih dan kinayah.

\section{Perdebatan Majaz dalam al-Qur’an}

Berkaitan dengan persoalan majaz, dalam sejarah peradaban pemikiran Islam secara historis, setidaknya ada 3 (tiga) kelompok yang berbeda pandangan. Pertama, Mu`tazilah yang secara dogmatis ajarannya banyak bersinggungan dengan majaz. Mereka menjadikan majaz sebagai senjata untuk memberikan interpretasi terhadap teks-teks yang tidak sejalan dengan dasar-dasar pemikiran mereka. Kedua, Dzahiriyah, kelompok yang menolak keberadaan majaz baik dalam bahasa maupun dalam al-Qur`an, dan sebagai konsekuensi mereka juga menolak adanya ta`wil (interpretasi). Pada intinya mereka menentang dengan keras pemahaman terhadap teks yang melampaui lahiriah bahasa. Ketiga, Asy`ariyah yang mengakui adanya majaz dengan persyaratan-persyaratan tertentu. Paling tidak mereka memposisikan 
diri secara moderat di antara dua kelompok di atas (Abu Zaid, 1994a:122).

Perbedaan pendapat berkenaan dengan eksistensi majaz dalam al-Qur'an disebabkan karena perbedaan analisis dan kesimpulan mengenai asal-usul bahasa. Kalangan $\mathrm{Mu}$ 'tazilah berkeyakinan bahwa bahasa semata-mata merupakan konvensi murni manusia. Sementara kalangan Dzahiriyah berkeyakinan bahwa bahasa merupakan pemberian Tuhan (tawqifi) yang diajarkan kepada Adam, dan setelah itu beralih kepada anak keturunannya. Berbeda dengan kelompok Asy`ariyah yang menyatakan, bahasa merupakan kreativitas manusia, akan tetapi tidak bisa dipungkiri bahwa Tuhan juga berperan dalam memberikan kemampuan kepada manusia.

Meminjam istilah Komaruddin Hidayat (1996:29), secara garis besar terdapat 3 (tiga) teori yang membahas tentang asal-usul bahasa, yaitu: 1) teologis, 2) naturalis, dan 3) konvensionalis. Pendukung aliran teologis mengatakan, manusia bisa berbahasa karena anugerah Tuhan, pada mulanya Tuhan mengajarkan kepada Adam selaku nenek moyang seluruh manusia. Pendukung teori yang bersifat naturalis, beranggapan bahwa kemampuan manusia berbahasa merupakan bawaan alam, sebagaimana kemampuan untuk melihat, mendengar maupun berjalan. Sedangkan pendukung teori konvensional berpandangan bahwa bahasa pada awalnya muncul sebagai produk sosial. Ia merupakan hasil konvensi yang disepakati dan kemudian dilestarikan oleh masyarakat.

Pertentangan mengenai asal-usul bahasa jauh sebelum pemikir muslim telah muncul dan menjadi polemik di kalangan filosof Yunani. Apakah bahasa itu dikuasai alam, nature atau fisei, ataukah bahasa itu bersifat konvensi atau nomos. Pendapat yang menyatakan bahwa bahasa adalah bersifat alamiah (fisei), yaitu bahasa mempunyai hubungan dengan asal-usul, sumber dalam prinsip-prinsip abadi dan tak dapat diganti di luar manusia itu sendiri, dan karena itu tak dapat ditolak. Kaum naturalis dengan tokoh-tokohnya, seperti Cratylus dalam dialog dengan Plato mengatakan bahwa semua kata pada umumnya mendekati benda yang ditunjuk. Jadi ada hubungan antara komposisi 
bunyi dengan apa yang dimaksud. Bahasa bukanlah hanya bersifat fisis belaka, melainkan telah mencapai makna secara alamiah, atau fisei.

Sebaliknya, kaum konvensionalis berpendapat bahwa makna bahasa diperoleh dari hasil-hasil tradisi, kebiasaan berupa persetujuan bersama. Karena itu, bahasa dapat berubah dalam perjalanan zaman. Bahasa bukanlah pemberian Tuhan, melainkan bersifat konvensional. Demikian pendapat Hermogenes saat berdialog dengan Plato (Kaelan, 1998:28).

Sikap menolak majaz terkait dengan anggapan yang intinya bahwa majaz adalah sahabat kebohongan, pembicara melakukan hal itu hanya ketika ungkapan yang hakiki sudah tidak memadai sehingga ia membuat ungkapan majaz. Hal ini tidak mungkin terjadi pada Allah. Karena itu, al-Qur'an wajib dibersihkan dari kemungkinan majaz termasuk di dalamnya. Ini tidak berarti bahwa majaz terjadi atau ada dalam bahasa, tetapi tidak ada dalam al-Qur`an. Sebab kalau tidak demikian, maka konsep semacam ini akan berbenturan dengan salah satu aksioma dasar, yaitu bahwa al-Qur'an diturunkan dengan bahasa Arab, dengan berdasarkan cara mereka mengekspresikannya. Ini merupakan aksiomatik yang didukung oleh al-Qur'an sendiri, sebagaimana pula ditegaskan oleh banyak penjelasan sarjana bahasa. Oleh karena itu, Ibn Qayyim al-Jawziyyah (w.751) menolak pembagian kata menjadi haqiqi dan majazi. Ia berpendapat bahwa mereka yang membagi ujaran menjadi haqiqi dan majazi tidak mendasarkan pada landasan rasional, atau syar iyah atau kebahasaan. Sebab akal tidak memiliki tempat dalam kaitannya makna kata dan spesifikasi kata terhadap makna yang diacunya, baik secara haqiqi ataupun metafosris. Karena acuan kata terhadap maknanya, seandainya bersifat rasional tentunya tidak seorangpun yang tidak mengetahui makna sebuah kata. Agama tidak menginginkan pembagian seperti itu, dan tidak satu pun ahli bahasa yang secara terang-terangan menegaskan bahwa bangsa Arab membagi bahasanya menjadi haqiqi dan majazi (Abu Zaid, 1994a:126). 
Konsekuensi menolak majaz berarti menolak adanya ta`wil, bahasa dimaknai seperti apa adanya. Bagaimana kalau dalam al-Qur'an ditemukan bahasa mutasyabih, seperti muka, tangan, wajah, dan sebagainya? Bagi kelompok yang menerima konsep majaz tentu bahasa tersebut sangat membutuhkan ta wil, karena Allah tidak memiliki sifat fisik seperti yang ada pada makhluk. Namun, bagi kelompok yang tidak mengakui adanya majaz dalam al-Qur'an maka ungkapan muka, tangan, wajah, dan sebagainya dipahamai secara skriptural, yang jelas muka, tangan, dan wajah Allah tidak sama dengan muka, tangan, dan wajah manusia, atau makhluk lainnya.

\section{Majaz, Tasybih dan Kinayah: Gaya Bahasa Retorik dalam al-Qur’an}

Dalam kajian gaya bahasa Arab modern konsep majaz lazim digunakan oleh para sarjana klasik sebagai lawan dari istilah haqiqah. Secara etimologis kata majaz tidak ditemukan dalam al-Qur'an, namun akar kata dari kata majaz, yaitu $j-w-z$, seperti jawwaza (memotong) dan tajawwaza (melewati) ada dalam al-Qur’an. Adalah Abd al-Qahir alJurjani $($ W.471 H) melalui penalaran dua konsep, yakni majaz versus haqiqah, ia mengatakan sebuah kata yang mengacu kepada makna asal atau makna dasar, tanpa mengundang kemungkinan makna lain disebut dengan haqiqah. Sedangkan majaz adalah ketika seseorang mengalihkan makna dasar ke makna lainnya karena alasan tertentu, atau ia bermaksud melebarkan medan makna dari makna dasarnya. Secara teoritik, menurut al-Jurjani majaz adalah peralihan makna dari yang leksikal menuju yang literer, atau dari yang denotatif menuju yang konotatif. Secara implisit, definisi di atas mengacu pada pengertian majaz mufrad, yakni majaz dalam kosa kata, sekaligus ia menunjukkan jenis majaz yang kedua yaitu majaz dalam kalimat. Pembagian ini dilandasi pada pertimbangan bahwa seseorang bisa merangkai majaz baik dalam bentuk kosa kata maupun dalam bentuk kalimat. Dan penggunaan ini sangat bergantung pada konteksnya (Setiawan, 2005:202). 
Dalam pandangan ulama ahli balaghah (ahli gaya bahasa retorika) konsep majaz sesungguhnya tidak ada perbedaan yang krusial dengan isti arah (peminjaman kata). Perbedaan keduanya terletak pada alaqah (relasi antara makna dasar dengan makna lain). Jika alaqah-nya musyabahah (ada kesesuaian antara makna dasar dengan makna lain) maka disebut isti arah, dan sebaliknya, jika ‘alaqah-nya gairu musyabahah (tidak ada kesesuaian) maka disebut majaz (Al-Hasyimi, 1960:291). Untuk lebih jelasnya perhatikan contoh berikut:

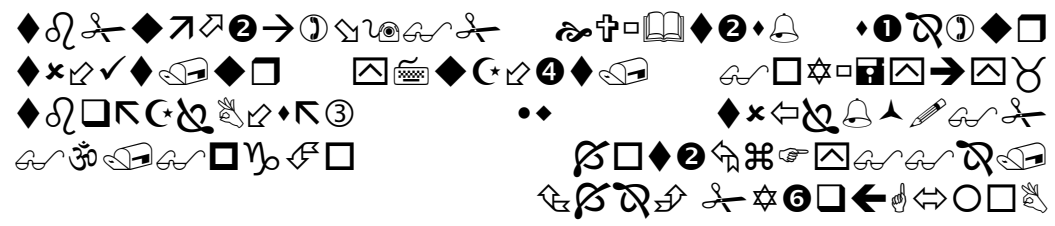

Artinya:"Dan apabila kamu membaca al-Qur'an niscaya Kami adakan antara kamu dan orang-orang yang tidak beriman kepada kehidupan akhirat, suatu dinding yang tertutup". (QS. Al-Isra' [17]:45)

Bentuk majaz pada ayat di atas adalah kalimat "hijaban masturan" (dinding yang tertutup). Menurut mayoritas mufassir maksudnya adalah dinding yang menutup, karena kata "masturan" bermakna menjadi sasaran, bukan sebagai pelaku. Jadi, arti yang tepat pada kata "masturan" adalah "satiran" (yang menutup). Di sini `alaqah-nya adalah ghairu musyabahah, yaitu tidak adanya kesesuaian antara makna dasar (masturan/yang ditutup) dengan makna lain (satiran). Pemahaman ini terjadi hanya berdasarkan pada logika dan kebiasaan semata, bukan dari sisi struktur kalimatnya.

Berbeda dengan ungkapan isti arah berikut ini:

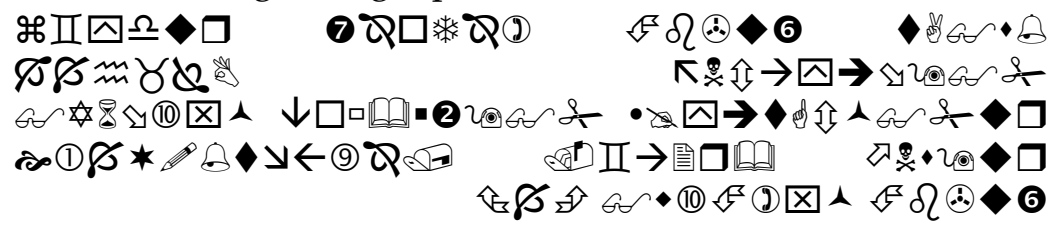


Artinya: "Ia Berkata "Ya Tuhanku, sesungguhnya tulangku telah lemah dan kepalaku telah ditumbuhi uban, dan Aku belum pernah kecewa dalam berdoa kepada Engkau, Ya Tuhanku" (QS. Maryam [19]:4).

Secara leksikal kata isyta ala bermakna "menyala", kata al-ra `su bermakna "kepala", dan kata syaiba bermakna "uban". Kurang tepat jika ungkapan tersebut diterjemahkan: "dan kepalaku menyala uban", namun yang benar adalah "dan kepalaku telah ditumbuhi uban". Perpindahan (penggunaan) makna isyta ala (menyala) kepada nabata (tumbuh) adalah keserupaan/kesesuaian (musyabahah), karena dalam ungkapan itu ada kata al-ra`su. Maksudnya, kata nabata diserupakan dengan isyta ala, sebab begitu banyaknya uban yang tumbuh di kepala. Kemudian kata nabata dibuang dan yang menjadi qarinah (indikator) adalah kata syaiba (uban). Qarinah yang dimaksud adalah kata atau keadaan yang tidak memperbolehkan sebuah kata diterjemahkan atau dipahami secara leksikal (haqiqi).

Termasuk katagori ungkapan majaz yang pernah berkembang di kalangan sarjana muslim klasik adalah tasybih. Istilah tasybih pertama kali dipakai pada era al-Mubarrad (w.286 H) dan Ibn al-Mu taz (w.296 $\mathrm{H})$, meskipun kata tersebut juga muncul pada era al-Farra' dan Abu Ubaidah, namun hanya sebatas sebagai tambahan penjelasan kebahasaan dan belum sampai pada pengertian sebagai diskursus ilmu bayan. Al-Jahiz (w.255 H) misalnya, meskipun dalam banyak karya ia tidak menjadikan tasybih sebagai obyek kajiannya, namun ia sudah mengulas dan mempergunakannya sebagai penopang argumentasinya akan keindahan ungkapan al-Qur'an (Abbas, 1987:18).

Al-Mubarrad (w.285 H) dalam karyanya yang berjudul "alKamil" memberikan ulasan tentang tasybih. Uraian al-Mubarrad dinilai oleh para kritikus sastra kontemporer sebagai sumbangan yang sangat berarti terhadap perkembangan tasybih dalam diskursus retorik Arab. Ia berpendapat, tasybih merupakan seni bertutur yang paling sering dipakai dalam bahasa Arab. Kajian khusus mengenai tasybih telah 
dilakukan oleh Ibn Abi 'Awn (w.323 H), di mana ia tidak saja membahas tasybih secara komprehensif, melainkan juga pelbagai macam syair semenjak era klasik sampai era Abbasiyah. Dalam karyanya "alTasybihat", ia menempatkan ayat-ayat al-Qur'an sebagai pijakan dan basis keindahan serta kesempurnaan kei jazan al-Qur`an. Tetapi kajian tasybih secara spesifik sebagai elemen ilmu bayan dalam kerangka sebagai dogma kei'jazan al-Qur'an baru diangkat oleh al-Rummani (w.386 H). Dibandingkan para sarjana sebelumnya, al-Rummani bukan saja membahas tasybih pada tataran teoritis tetapi ia sudah masuk bagaimana al-Qur'an bisa dilacak keindahan sastranya melalui tasybih. Embrio pemikiran tasybih di atas kemudian disempurnakan oleh Abd alQahir al-Jurjani (w.471 H), di mana ia lebih menjelaskan perbedaan antara tasybih dan tamstil.

Secara etimologis tasybih berarti penyerupaan. Sedangkan secara terminologis adalah menyerupakan dua perkara atau lebih yang memiliki kesamaan dalam hal tertentu (Al-Hasyimi, 1960:247). Para sastrawan Arab menjelaskan bahwa tasybih merupakan elemen vital dalam karya sastra. Menurut mereka tasybih memiliki empat unsur utama, yaitu; i) sesuatu yang diperbandingkan (al-musyabbah), ii) obyek perbandingan (al-musyabbah bih), iii) alasan perbandingan (wajh al-syibh), dan iv) perangkat perbandingan (adat al-tasybih). Sedangkan almusyabbah dan musyabbah bih disebut tharafan al-tasybih, yaitu dua pilar yang harus ada dalam ungkapan kalimat yang berbentuk tasybih. Apabila salah satu yang muncul, apakah itu musyabbah atau musyabbah bih maka pembahasan ini bukan termasuk kategaori tasybih, melainkan masuk pada kajian istiarah. Karena itu, konsep majaz, isti arah, dan tasybih mempunyai kaitan dan saling berhubungan.

Ahmad Badawi (1950:190) mengatakan, tasybih berfungsi memperjelas makna serta memperkuat maksud dari sebuah ungkapan. Sehingga orang yang mendengarkan pembicaraan bisa merasakan seperti pengalaman psikologis si pembicara. Dalam persoalan-persoalan yang berkaitan dengan eskatologis al-Qur'an seringkali digunakan bahasa metaforis yang diungkapkan dalam bentuk gaya bahasa simile (tasybih). Karena bahasa metaforis memiliki kekuatan yang bisa 
mempertemukan antara ikatan emosional dan pemahaman kognitif sehingga seseorang dimungkinkan mampu melihat dan merasakan sesuatu yang berada jauh di belakang teks. Contohnya adalah gambaran sifat-sifat penghuni neraka yang dideskripsikan al-Qur'an dalam surat al-A 'raf ayat 179 sebagai berikut:

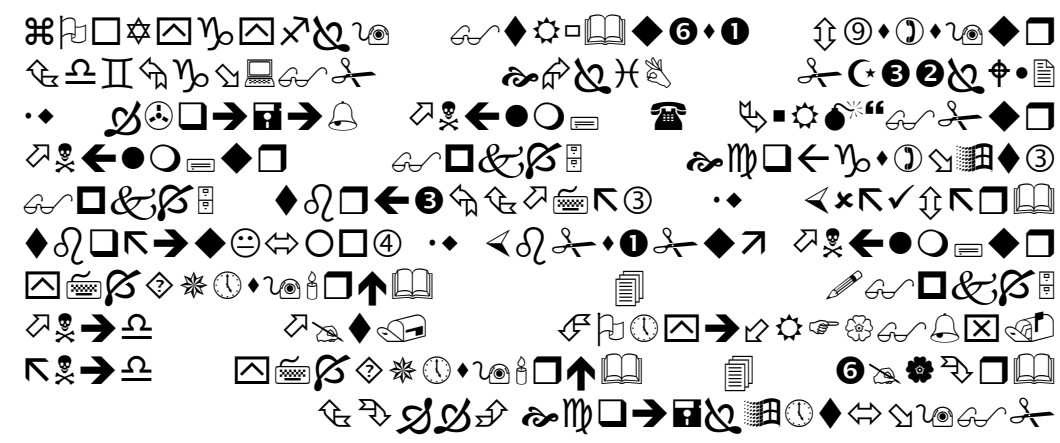

Artinya: "Dan sesungguhnya Kami jadikan untuk isi neraka Jahannam kebanyakan dari jin dan manusia, mereka mempunyai hati, tetapi tidak dipergunakannya untuk memahami (ayat-ayat Allah), dan mereka mempunyai mata (tetapi) tidak dipergunakannya untuk melihat (tanda-tanda kekuasaan Allah), dan mereka mempunyai telinga (tetapi) tidak dipergunakannya untuk mendengar (ayat-ayat Allah). Mereka itu seperti binatang ternak, bahkan mereka lebih sesat lagi. Mereka itulah orang-orang yang lalai" (QS. Al-A'raf [7]:179).

Kandungan tasybih dalam ayat di atas adalah "ula 'ika kal an 'am" (mereka seperti binatang ternak). Sebuah gaya bahasa yang ringkas, padat, jelas, dan penuh dengan makna. Orang-orang yang kufur terhadap ni mat Allah, seperti orang yang dikaruniai hati tapi tidak dipergunakan untuk tadabbur, dikaruniai penglihatan tapi tidak dipergunakan untuk melihat kebesaran-Nya, dan dikaruniai telinga tapi tidak dipergunakan untuk mendengar ayat-ayat Allah maka Allah cukup mempersamakan mereka dengan satu ungkapan, yaitu "binatang ternak", bahkan lebih sesat. 
Juga contoh lain, bagaimana al-Qur'an memberikan kabar gembira kepada orang yang beriman dan berbuat kebaikan? Perhatikan ayat berikut:

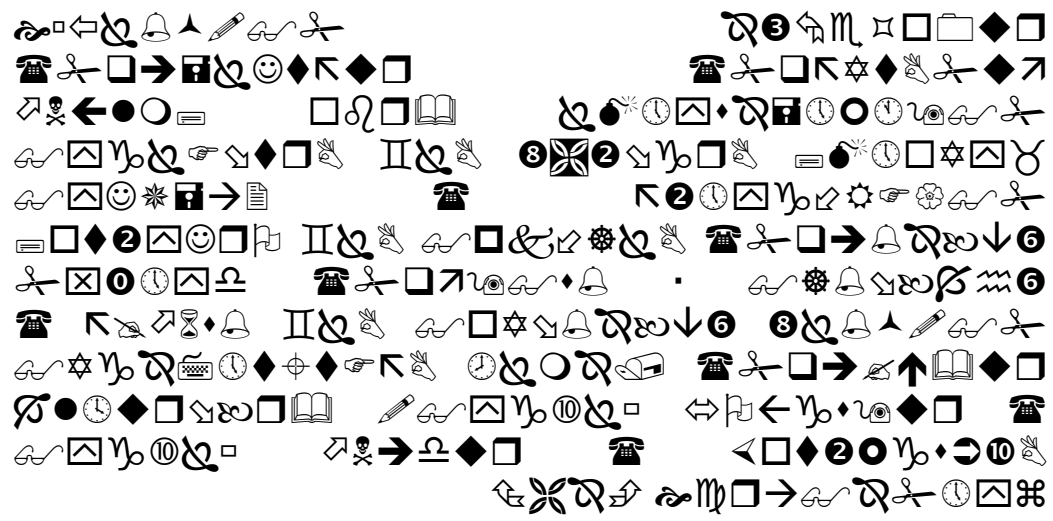

Artinya:"Dan sampaikanlah berita gembira kepada mereka yang beriman dan berbuat baik, bahwa bagi mereka disediakan surgasurga yang mengalir sungai-sungai di dalamnya. Setiap mereka diberi rezki buah-buahan dalam surga-surga itu, mereka mengatakan, inilah yang pernah diberikan kepada kami dahulu. Mereka diberi buah-buahan yang serupa dan untuk mereka di dalamnya ada isteri-isteri yang suci dan mereka kekal di dalamnya" (QS. Al-Baqarah [2\}:25).

Sebuah perumpamaan yang dapat memikat hati masyarakat Arab, jika mereka beriman dan berbuat baik maka baginya surga yang penuh dengan air, buah-buahan, dan isteri-isteri. Tidak bersahabatnya kondisi alam membuat mereka kekurangan sumber mata air, serta tandusnya tanah padang pasir mengakibatkan sulitnya untuk mendapatkan bahan makanan. Peperangan-peperangan yang terjadi di antara mereka banyak disebabkan oleh kebutuhan pokok tersebut, dan bahkan dipicu oleh kecintaan kepada seorang wanita.

Kebutuhan fisik berupa air dan buah-buahan, serta kebutuhan biologis berupa isteri-isteri (bentuk jamak) merupakan fenomena dan 
realita yang menimpa masyarakat Arab. Untuk menggugah keyakinannya, agar mereka mau beriman kepada ajaran yang dibawa Nabi dan kemudian diwujudkan dalam bentuk perbuatan nyata maka al-Qur'an menyampaikan dengan gaya bahasa tasybih. Surga yang digambarkan suatu tempat yang penuh dengan air, buah-buahan, dan isteri-isteri adalah bentuk perumpamaan yang dapat memberikan stimulus, membangkitkan sugesti, dan menjadi dambaan dalam hidup mereka.

Al-Mubarrad (w.258 H) merupakan sarjana bahasa yang melakukan sistematisasi mengenai konsep kinayah. Dalam karyanya "alKamil", al-Mubarrad menguraikan 3 (tiga) model kinayah beserta fungsinya, yaitu: 1) menjadikan sesuatu lebih umum, 2) memperindah ungkapan, dan 3) untaian pujian. Namun al-Mubarrad tidak banyak mengulas pada model pertama dan ketiga, ia lebih menitikberatkan pada model yang kedua, yaitu kinayah sebagai penyempurna keindahan ungkapan, khususnya yang diambil dari ayat-ayat al-Qur`an.

Kinayah adalah mengungkapan kata, tetapi yang dimaksud bukan makna dari kata itu, sekalipun bisa dibenarkan kalau dipahami sesuai dengan makna dasarnya. Misalnya dalam pribahasa Arab " طويل "اليد" (tangan panjang). Di kalangan orang Arab sangat popular istilah "alyad al-thawilah" untuk menyebut (sebagai kinayah) kepada seseorang yang suka memberi atau membantu. Tetapi kalau "al-yad al-thawilah" dipahami sebagai tangan yang panjang, sesuai dengan makna dasarnya juga tidak salah, inilah kinayah. Perhatikan pula dalam surat al-Zukhruf ayat 18 berikut ini:

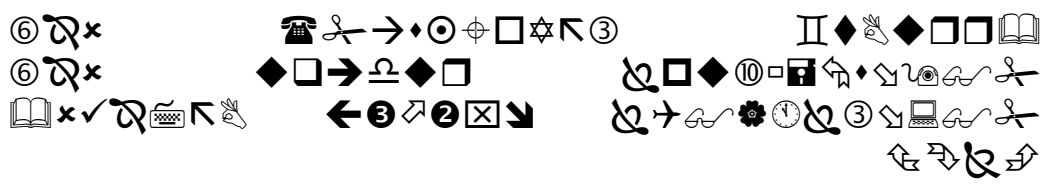

Artinya: "Dan apakah patut (menjadi anak Allah) orang yang dibesarkan dalam keadaan berperhiasan sedang dia tidak dapat memberi alasan yang terang dalam pertengkaran" (QS. AlZukhruf [43]:18). 
Menurut Fadlal Hasan, ayat tersebut diturunkan kepada Nabi yang dilatarbelakangi oleh kebiasaan orang Arab jahilayah yang membenci anak-anak perempuan dan menguburnya hidup-hidup. Selain itu, mereka juga menyangka bahwa malaikat itu anak perempuan Allah. Kemudian ayat tersebut diturunkan sekaligus memperkuat kebodohan dan kedangkalan pemikiran mereka. Dalam ungkapan ayat di atas "man yunasysya 'u fil hilyati" (orang yang dibesarkan dalam keadaan berperhiasan) adalah kinayah bagi seorang wanita. Karena yang sering berhias dan berdandan, serta tidak memiliki kekuatan dalam pertengkaran adalah wanita. Jadi, konteks ayat di atas sebagai kinayah bagi orang perempuan Arab jahili yang memiliki kebiasaan berhias diri dan tidak punya kekuatan, sekalipun sifat-sifat itu juga terdapat pada perempuan zaman sekarang.

\section{Penutup}

Dalam telaah sosiolinguistik disebutkan, ketika aktivitas bicara berlangsung, ada dua faktor yang turut menentukan, yaitu faktor situasional dan sosial. Faktor situasi turut mempengaruhi pembicaraan terutama pemilihan kata-kata dan bagaimana cara mengkode, sedangkan faktor sosial menentukan bahasa yang dipergunakan. Bertalian dengan aktivitas bicara ini kemudian lahirlah ungkapan bahasa di mana preferensi kata atau kalimat benar-benar menjadi pertimbangan agar bahasa itu menjadi komunikatif.

Bahasa al-Qur'an memiliki karakteristik yang berbeda dengan bahasa-bahasa lainnya. Karena bahasa al-Qur`an bukan hanya mengacu pada dunia empiris, tetapi juga mengatasi ruang dan waktu, bahkan bersifat metafisik. Maka untuk memahaminya tidak mungkin hanya dengan berdasarkan pada kaidah-kaidah linguistik, namun diperlukan bahasa perbandingan (perumpamaan). Karena itu, sangat dimaklumi apabila dalam al-Qur`an dijumpai ungkapan-ungkapan metaforiksimbolik yang lazim di kalangan sastrawan Arab dikenal dengan istilah majaz, tasybih dan kinayah yang dapat membantu pikiran manusia yang 
terbatas dengan dunia metafisik yang tak terbatas. Seperti yang disebutkan dalam analisis psikolinguistik bahwa untuk sampai pada tahap pemikiran konseptual diperlukan tahapan-tahapan. Sementara proses berpikir dan berbahasa memiliki keterkaitan erat dengan perkembangan jiwa seseorang. Sebab itu dalam setiap bahasa dan tradisi agama selalu terdapat ikon-ikon dan simbolisasi dari Realitas Absolut yang kemudian dihadirkan dalam wujud bahasa manusia. $\square$ 


\section{DAFTAR PUSTAKA}

Abbas, Fadlal Hasan. 1987. Al-Balaghah Fununuha wa Afnanuha. Aman: Dar al-Furqan.

Abu Zaid, Nasr Hamid. 1994a. Isykaliyat al-Qira`ah wa Aliyat al-Ta`wil. Kairo: Al-Markaz Al-Tsaqafi Al-'Arabi.

Abu Zaid, Nasr Hamid. 1994b. Naqd al-Khithab al-Diniy. Kairo: Jumhuriyah Misr al-'Arabiyah.

Abu Zaid, Nasr Hamid. 1996. Al-Ittijah Al-`Aqli fi Al-Tafsir: Dirasah fii Qadhiyah Al-Majaz fii Al-Qur'an 'Inda Al-Mu'tazliah. Kairo: alMarkaz al-Tsaqafi al-'Arabi.

Al-Hasyimi, Ahmad. 1960. Jawahir al-Balaghah. Indonesia: Dar Ihya alKutub al-Arabiyah.

Al-Qatthan, Manna'. Tanpa tahun. Mabahits fi 'Ulum al-Qur'an. Tanpa tempat: Tanpa penerbit

Badawi, Ahmad Ahmad. 1950. Min Balaghah Al-Qur'an. Kairo: Dar alNahdlah.

Hidayat, Komaruddin. 1996. Memahami Bahasa Agama: Sebauh Kajian Hermeneutik. Jakarta: Paramadina.

Izutsu, Toshihiko. 1997. Relasi Tuhan dan Manusia: Pendekatan Semantik Terhadap al-Qur'an. Yogyakarta: PT Tiara Wacana.

Kaelan, M.S. 1998. Filsafat Bahasa Masalah dan Perkembangannya. Yogyakarta: Paradigma.

Kaelan, M. S. 2003. "Kajian Makna al-Qur'an (Suatu Pendekatan Analitika Bahasa)", dalam Hermeneutika al-Qur'an Mazhab Yogya. Yogyakarta: Islamika.

Keraf, Gorys. 2004. Diksi dan Gaya Bahasa. Jakarta: PT Gramedia Pustaka Utama. 
Lasyin, Abd al-Fattah. 1985. Al-Bayan fi Dlau`i Asalib Al-Qur`an. Beirut: Dar al-Ma`arif.

Mulyana, Deddy. 2001. Ilmu Komunikasi Suatu Pengantar. Bandung: PT Remaja Rosdakarya.

Murata, Sachiko. 1999. The Tao of Islam. Bandung: Mizan.

Setiawan, M. Nur Kholis. 2005. Al-Qur'an Kitab Sastra Terbesar. Yogyakarta: eLSAQ Press.

Wahab, Abdul. 1998. Isu Linguistik Pengajaran Bahasa dan Sastra. Surabaya: Airlangga University Press. 